\title{
A comparative clinical study between intra-caesarean and interval intra uterine copper device insertion in caesarean deliveries
}

\author{
Geetha Lakshmi R. ${ }^{1 *}$, Sornam M. S. ${ }^{2}$, Thenmozhi G. ${ }^{3}$
}

\begin{abstract}
${ }^{1}$ Department of Obstetrics and Gynecology, Dhanalakshmi Srinivasan Medical College and Hospital, Perambalur, Tamil Nadu, India

${ }^{2}$ Department of Obstetrics and Gynecology, Tagore Medical College and Hospital, Chennai, Tamil Nadu, India ${ }^{3}$ Department of Obstetrics and Gynecology, Chengalpattu Medical College and Hospital, Chengalpattu, Tamil Nadu, India
\end{abstract}

Received: 10 August 2019

Accepted: 31 August 2019

\section{*Correspondence:}

Dr. Geetha Lakshmi R.,

E-mail: glakshmii06@gmail.com

Copyright: $\odot$ the author(s), publisher and licensee Medip Academy. This is an open-access article distributed under the terms of the Creative Commons Attribution Non-Commercial License, which permits unrestricted non-commercial use, distribution, and reproduction in any medium, provided the original work is properly cited.

\begin{abstract}
Background: Health and family welfare of Indian Ministry, emphasis on postpartum IUCD insertion. Here we conducted a clinical study comparing intra-caesarean and interval CuT-380A insertion in caesarean deliveries.

Methods: A systematic study with 150 patients in each group, recruited clients alternately. Group A Intra-Caesarean $\mathrm{Cu}-\mathrm{T}$ insertion and Group B Interval $\mathrm{Cu}-\mathrm{T}$ insertion in caesarean deliveries. Groups were followed up at $6^{\text {th }}$ week and $6^{\text {th }}$ month post insertion with a set of parameters. Missed strings, expulsion and infection rates were the primary outcome measures.

Results: Infection rate is higher in Group A $(2.3 \%)$ at $6^{\text {th }}$ week, and at $6^{\text {th }}$ month infection rate is higher in Group B $(1.8 \%)$. Missed strings are higher in intra-caesarean than in interval insertion method both at $6^{\text {th }}$ week and $6^{\text {th }}$ month follow up $\mathrm{p}=0.000$, hence significant. Expulsion rate is higher in Group A $(2.5 \%)$ at $6^{\text {th }}$ week, and at $6^{\text {th }}$ month expulsion rate is higher in Group B (1.9\%). There are no complications such as uterine perforation or contraceptive failures in both the groups during the study period. By analysis, there are no significant differences in infection and expulsion rates between the groups. For missed strings there is significant difference between the groups with more missed strings in intra-caesarean insertion method.

Conclusions: To conclude, intra-caesarean method is equally effective as interval IUCD insertion method without added complications in caesarean deliveries, with advantage of high motivation, good compliance, safety and ease for the provider to deliver services.
\end{abstract}

Keywords: Caesarean delivery, Intra-caesarean, Interval, IUCD, Postpartum

\section{INTRODUCTION}

With the background of steady increase in population, emphasis on family planning methods including contraception becomes more critical. It is not only dealt by medical profession but also constrained by social, religious and political groups. In this way Government of India, as a part of family planning, introduced $\mathrm{Cu}-\mathrm{T} 380 \mathrm{~A}$ in 2002 by replacing the previous $\mathrm{Cu}-\mathrm{T}$ 200.The acceptance of IUCD continues to remain less than $2 \%$, out of the total CPR of $48.5 \%$. $^{1}$

The aim of National population policy 2000 is to attain a stable population, gender and demographic balance by 2045. Providing quality contraception services to women is one of the cornerstones of MDG goals to improve 
maternal and child health. Most of the women in the postpartum period want to accept a contraception method to regulate their fertility either by spacing or limiting future pregnancies. So, the postpartum family planning services have to be strengthened and the providers are in need to be updated on recent developments in contraceptive services. ${ }^{1}$

In order to reduce the unmet need for contraception in the post-partum period, Postpartum IUCD is an important step which also promotes maternal and child health. ${ }^{1}$ Safe and effective contraceptive services in the postpartum period are of utmost importance for a woman to prevent unwanted/mistimed pregnancy. Immediate postpartum IUCD insertion is an effective and safe contraception which can be accepted by the woman immediately after delivery. The aim of this study is to assess the acceptability, effectiveness and safety of immediate intracaesarean IUCD insertion compared with extended postpartum (Interval) IUCD insertion in caesarean deliveries.

\section{METHODS}

A systematic clinical study was conducted in the Department of Obstetrics and Gynecology at Chengalpattu Medical College Hospital, Chengalpattu from October 2012 to October 2013, which was approved by Ethical Committee.

This is a randomized clinical trial, parallel assignment on alternate basis, non-blinding method. Purpose is contraception. This study includes 300 patients out of the 500 patients, who were motivated in the labour ward, assigned 150 patients in each group systematically on alternate basis who gave consent. Remaining 200 patients not have given consent. The study population was assigned into two groups. Group A: IUCD Cu-T 380A was inserted intra-uterinely during the caesarean section, before closing the uterine incision. Group B: IUCD Cu-T 380 A was inserted after 6 weeks and within one year of caesarean delivery by withdrawal technique. Patients were categorized into Group A and Group B on alternate basis after giving a proper pre-op/pre-insertion counseling regarding the time of IUCD insertion. The counseling was given by either post graduate or senior staff nurse on duty.

\section{Inclusion criteria}

- Includes emergency or elective caesarean deliveries (primipara, multipara not willing for sterilization), age more than 18 years but less than 49 years, patients between 6 weeks and one year after caesarean delivery for interval insertion.

\section{Exclusion criteria}

- Vaginal deliveries, miscarriages, within 6 weeks after caesarean delivery, multipara willing for sterilization, prolonged rupture of membranes $>18$ hours, features suggestive of chorioamnionitis or puerperal sepsis, intrapartum or postpartum hemorrhage.

- Contraindications of IUCD insertion such as recurrent pelvic infections, lower genital tract infections, presence of one or more fibroids, severe anemia.

- Complicated cases such as eclampsia, heart failure, uterine anomalies, purulent discharge per vaginum, extensive genital injuries, disagreement to participate in the study were excluded from this study.

Before discharge in Group A and after insertion in Group $\mathrm{B}$, all the patients were instructed about probable side effects and complications of IUCD insertion. Patients were shown CUT 380 A how it looks like, its safety and told about its protection period (10 years). Patients were informed about the checking of IUCD threads and were instructed to notice expulsion if any. They were advised to review in op clinic if they have warning signs like irregular bleeding, abdominal pain, dyspareunia, abnormal vaginal discharge, missing threads, and feeling of IUCD in the vagina.

Both Group A and Group B patients were followed up at $6^{\text {th }}$ week and $6^{\text {th }}$ month after insertion with a set of questionnaire, internal examination and USG abdomen and pelvis.

- To interpret for infection, based on CDC criteria for PID, patients presented with abdominal cramps associated with fever $>101^{\circ} \mathrm{F}$, uterine or adnexal tenderness, elevated ESR or excessive/offensive vaginal discharge on wet mount examination showing >10 polymorphs/ HPF were considered to have pelvic infection

- To interpret for Missing thread, patients whose IUCD threads; i) curled within uterine cavity, ii) were cut-off spontaneously, iii) those that expelled spontaneously and iv) those that perforated into abdominal cavity were included

- For IUCD expulsion, patients with missing threads were done USG to confirm its absence.

\section{Statistical analysis}

The data were collected and the statistical analysis was done with Epi info 7 programs. The group comparison for quantitative variables were analyzed using independent student t-test. The group comparisons for qualitative variables were analyzed using Chi-square analysis and Fishers exact test wherever necessary. In all analysis $\mathrm{p}<0.05$ considered as statistically significant.

\section{RESULTS}

In our study, most of the acceptors were primipara, 131 $(87 \%)$ in Group A and $132(88 \%)$ in Group B. Whereas the acceptors among second gravida were least 19 (13\%) 
in Group A and $18(12 \%)$ in Group B. Multipara preferred the permanent method of sterilization. Majority of the study people studied up to high school $59 \%$ in Group A and 55\% in Group B, followed by diploma $22 \%$ in Group A and $21 \%$ in Group B, degree holders were $6 \%$ in both the groups. Our study showed that majority of the acceptors were in the age group of 21-25 years, $83 \%$ in Group A and $79 \%$ in Group B. Least acceptors were found in the age group of 18-20 years, $7 \%$ in Group A and $10 \%$ in Group B.

Table 1: Sixth week follow up of Group A and Group B.

\begin{tabular}{|llll|}
\hline $6^{\text {th }}$ week follow up & Group A $(\mathrm{N}=126)$ & Group B (N=122) & p value \\
\hline Lower abdominal cramp & $10(7.9 \%)$ & $8(6.6 \%)$ & 0.676 \\
\hline Presence of menstrual irregularities & $8(6.3 \%)$ & $4(3.3 \%)$ & 0.260 \\
\hline Excessive vaginal discharge & $11(8.7 \%)$ & $12(9.8 \%)$ & 0.828 \\
\hline Infection & $3(2.3 \%)$ & $2(1.6 \%)$ & 1.0000 \\
\hline History of IUCD removal & $4(3.2 \%)$ & $3(2.5 \%)$ & 0.734 \\
\hline Threads seen on per speculum & $52(41.3 \%)$ & $113(92.6 \%)$ & 0.000 \\
\hline IUCD not found confirmed by USG & $7(5.6 \%)$ & $5(4.1 \%)$ & - \\
\hline IUCD expelled & $3(2.5 \%)$ & $2(1.7 \%)$ & 1.000 \\
\hline Missed strings & $67(53.17 \%)$ & $4(3.2 \%)$ & 0.000 \\
\hline Lost follow up n=150 & $24(16.0 \%)$ & $28(18.7 \%)$ & 0.647 \\
\hline
\end{tabular}

IUCD: Intrauterine copper device, USG: Ultrasonogram.

Table 2: Sixth month follow up of Group A and Group B.

\begin{tabular}{|llll|}
\hline $6^{\text {th }}$ month follow up & Group A $(\mathrm{N}=116)$ & Group B (N=112) & p value \\
\hline Lower abdominal cramp & $8(6.9 \%)$ & $4(3.6 \%)$ & 0.261 \\
\hline Presence of menstrual irregularities & $4(3.4 \%)$ & $2(1.8 \%)$ & 0.433 \\
\hline Excessive vaginal discharge & $5(4.3 \%)$ & $6(5.3 \%)$ & 0.765 \\
\hline Infection & $1(0.9 \%)$ & $2(1.8 \%)$ & 0.617 \\
\hline History of IUCD removal & $10(8.6 \%)$ & $4(3.6 \%)$ & 0.112 \\
\hline Threads seen on per speculum & $54(46.6 \%)$ & $103(92 \%)$ & 0.000 \\
\hline IUCD not found confirmed by USG & $10(8.6 \%)$ & $6(5.4 \%)$ & - \\
\hline IUCD expelled & $0(0.0 \%)$ & $2(1.9 \%)$ & 0.497 \\
\hline Missed strings & $52(44.8 \%)$ & $3(2.6 \%)$ & 0.000 \\
\hline Lost follow up n=150 & $34(22.7 \%)$ & $38(25.3 \%)$ & 0.685 \\
\hline
\end{tabular}

IUCD: Intrauterine copper device, USG: Ultrasonogram.

During the follow up, at $6^{\text {th }}$ week, lower abdominal cramp present in $7.9 \%$ in Group A and $6.6 \%$ in Group B, $(p=0.676)$ hence not significant. At 6th month, it is $6.9 \%$ in Group A and 3.6\% in Group B, $(p=0.261)$ hence not significant.

At $6^{\text {th }}$ week, menstrual irregularities present in $6.3 \%$ in Group A and $3.3 \%$ in Group B, $(\mathrm{p}=0.260)$ hence not significant. At $6^{\text {th }}$ month, it is $3.4 \%$ in Group A and $1.8 \%$ in Group $B,(p=0.433)$ hence not significant.

At $6^{\text {th }}$ week, excessive vaginal discharge present in $8.7 \%$ in Group A and $9.8 \%$ in Group B, $(\mathrm{p}=0.828)$ hence not significant. At 6 th month, it is $4.3 \%$ in Group A and $5.3 \%$ in Group $B,(p=0.765)$ hence not significant.

Infection rate is found to be higher in Group A $(2.3 \%)$ than in Group B $(1.6 \%) \mathrm{p}=1.000$, hence not significant at $6^{\text {th }}$ week. At $6^{\text {th }}$ month, infection rate is higher in Group B
(1.8\%) than in Group A $(0.9 \%) \mathrm{p}=0.617$, hence not significant.

At $6^{\text {th }}$ week, missed strings present in $53.2 \%$ in Group A which is higher than in Group B $(3.2 \%) \mathrm{p}=0.000$, hence significant. At $6^{\text {th }}$ month it is $44.8 \%$ in Group A which is higher than in Group B $(2.6 \%) \mathrm{p}=0.000$, hence significant. This is due to the curling of strings within the uterine cavity in intra-caesarean technique. Expulsion rate is found to be higher in Group $\mathrm{A}(2.5 \%)$ than in Group B (1.7\%) p=1.000 at $6^{\text {th }}$ week, hence not significant. At $6^{\text {th }}$ month there is no IUCD expulsion in Group A (0\%) but in Group B there is $(1.9 \%)$ expulsion $\mathrm{p}=0.497$, hence not significant (Table 1 , Table 2).

\section{DISCUSSION}

The need for contraception is highly warranted in our country, since approximately $27 \%$ of births occur in less 
than 24 months after a previous birth. Another $34 \%$ of births occur between 24 and 36 months. So the term birth-to-pregnancy interval is important, which is the time period between a live birth and the start of the next pregnancy. After a live birth, a woman should wait at least 24 months (but not more than five years) before attempting the next pregnancy. After a spontaneous or induced abortion, a woman should wait at least 6 months before attempting the next pregnancy. ${ }^{1}$ During this period, women need to be protected from pregnancy. She is in need of contraception. Copper containing IUCD Cu$\mathrm{T} 380 \mathrm{~A}$ will be the best option in view of easy \& onetime insertion, i.e. effective for 10 years and also costeffective. $^{1}$

Among various types of contraception our study deals with Postpartum IUCD insertion especially in caesarean deliveries. The specific advantages of postpartum insertion include: Convenience, high motivation, safe because she is not pregnant at the time of insertion. No effect on amount and quality of breast milk. The woman will have an effective method of contraception before discharge from hospital. For the service provider it saves the time, as insertion is performed on the same delivery table. Additional evaluations and separate clinical procedure is not required. Need for minimal additional instruments, supplies and equipment. Giving proper spacing of births results in good healing of uterine scar which reduces the chance of rupture uterus. ${ }^{2}$

Many studies compare the expulsion rate of post placental IUCD insertion among vaginal and caesarean deliveries, showed lower expulsion rate with intra caesarean IUCD insertion. In our study we compared immediate intra-caesarean IUCD insertion Group A and interval IUCD insertion Group B in caesarean deliveries. Similar to post placental IUCD insertion it has the advantage of high motivation, assurance that the woman is not pregnant and good compliance. Here we studied on 150 cases in each group. The cases were followed up at $6^{\text {th }}$ week and $6^{\text {th }}$ month after insertion with set of parameters. Here we look for infection rate, expulsion rate and missed string as primary outcome measures and complications as secondary outcome measure.

Muller L et al, a comparative study on expulsion rate of immediate IUD insertion after vaginal birth and after caesarean section. ${ }^{3} \mathrm{He}$ found that the expulsion rate is more with vaginal delivery $27.8 \%$ than in caesarean birth 0\% clinically. Kapp N, Curti KM et al, they analyzed 297 articles, all studies examined the outcomes of copper IUD insertions within the postpartum period compared to other time intervals. ${ }^{4}$ They conclude, no increase in risk of complications those who had an IUD inserted during the postpartum period. However, some increase in expulsion rates occurred with delayed postpartum insertion when compared to immediate insertion and with immediate insertion when compared to interval insertion, intra caesarean cases are associated with lower expulsion rates than post placental vaginal insertions, without increasing rates of post-operative complications. Nelson et al, showed no expulsion at 6 weeks follow up. ${ }^{5}$ Celen $S$ et al, in a study showed, Immediate post placental IUD insertion during caesarean section provides adequate protection against pregnancy. ${ }^{6}$ But the expulsion rate is higher, $17.6 \%$ per year. Levi E et al, conducted a cohort study on post placental IUD insertion showed no IUD expulsion at 6 weeks and 6 months, although the follow up rate is low 50\%. ${ }^{7}$ Singal $\mathrm{S}$ et al, in a study showed, expulsion rate of $5.33 \%$ at one year in immediate postplacental IUD insertion in caesarean deliveries. ${ }^{8}$ Lester $\mathrm{F}$ et al, conducted a randomized controlled study similar to our study. ${ }^{9}$ In their study, infection and expulsion were rare and did not differ between groups on analyses.

Norman et al, review of twelve eligible studies of postplacental IUD insertion after cesarean section included four randomized controlled trials of post-placental versus delayed insertion. ${ }^{10}$ Women randomized to delayed insertion were less likely to receive a device. Six studies examined the problem of missing IUD threads at followup with only $30 \%-60 \%$ presence of strings observed. They concluded that the IUD is a long-acting reversible contraceptive method that is suitable for use in all women undergoing CS. The problems of device expulsion, missing threads at follow-up, and the tendency of increased puerperal bleeding need to be solved.

To infer, in our study the missed strings are found to be higher in intra-caesarean Group A than in interval method Group B. Regarding infection and expulsion rates there is no significant difference between intra-caesarean and interval method within the period of 6 months follow up.

\section{CONCLUSION}

Based on the above discussion and studies it is found that postpartum IUCD insertion is an excellent method of contraception. In our study we have shown the comparison between intra-caesarean IUCD insertion and interval IUCD insertion. Results initially showed difference in lower abdominal cramp, menstrual irregularities, excessive vaginal discharge, infection, missed string and expulsion rates between the groups. But on statistical analysis, there found to be no significant difference in lower abdominal cramp, menstrual irregularities, excessive vaginal discharge, infection and expulsion rates between the groups.

For missed strings, there is a significant difference between the groups with more missed strings on intracaesarean method. The other disadvantage of intracaesarean method is removal of IUCD may require anesthesia or hysteroscopic guidance because of high rates of missed strings.

To conclude, intra-caesarean $\mathrm{Cu}-\mathrm{T}$ 380A is equally effective as interval IUCD insertion without any added complications (except for high Missed string rates) for contraception in caesarean deliveries within the period of 
6 months follow up, with added advantage of high motivation, good compliance, safety and ease for provider to deliver the services.

Funding: No funding sources

Conflict of interest: None declared

Ethical approval: The study was approved by the Institutional Ethics Committee

\section{REFERENCES}

1. Reference manual, post-partum IUCD, family planning division, Ministry of Health and Family Welfare, Government of India, Nirman Bhawan, New Delhi; 2010. Available at: http://www.nrhmtn.gov.in/modules/PPIUCD\%20Ref erence\%20Manual.pdf.

2. Reference manual, counseling for post-partum family planning and post-partum IUCD, family planning division, Ministry of Health and Family Welfare, Government of India, Nirman Bhawan, New Delhi; 2012. Available at: http://www.nrhmtn.gov.in/modules/PPFP\%20\&\%20 PPIUCD\%20Counseling\%20Ref\%20Manual\%20$\% 20$ English.pdf.

3. Letti Müller AL, Lopes Ramos JG, Martins-Costa SH. Transvaginal ultra-sonographic assessment of the expulsion rate of intrauterine devices inserted in the immediate postpartum period: a pilot study. Contra. 2005;72(3):192-5.

4. Kapp N, Curtis KM. Intrauterine device insertion during the postpartum. Contra. 2009;80:327-36.
5. Nelson A, Chen S, Eden R. Intraoperative placement of the Copper T-380 intrauterine devices in women undergoing elective caesarean delivery: a pilot study. Contra. 2009;80(1):81-3.

6. Celen S, Sucak A, Yildez Y, Danisman N. Immediate post placental insertion of an intrauterine contraceptive device during cesarean section. Contra. 2011;84(3):240-3.

7. Levi E, Cantillo E, Ades V, Banks E, Murthy A. Immediate post placental IUD insertion at caesarean delivery: a prospective cohort study. Contra. 2012;86(2):102-5.

8. Singal S, Bharti R, Dewan R. Clinical outcome of post placental Copper T 380A insertion in women delivering by caesarean section. J Clin Diagn Res. 2014;8(9):OC01-OC04.

9. Lester F, Kakaire O, Byamugisha J. Intracaesarean insertion of the Copper T380A versus 6 weeks post caesarean: a randomized clinical trial. Contra. 2015;91(3):198-203.

10. Goldstuck ND, Steyn PS. Insertion of intrauterine devices after cesarean section: a systematic review update. Int J Women's Health. 2017;9:205-12.

Cite this article as: Lakshmi RG, Sornam MS, Thenmozhi G. A comparative clinical study between intra-caesarean and interval intra uterine copper device insertion in caesarean deliveries. Int J Reprod Contracept Obstet Gynecol 2019;8:3874-8. 